\title{
EXERCISE THERAPY IN PATIENTS WITH RHEUMATOID ARTHRITIS AND OSTEOARTHRITIS: A REVIEW
}

\author{
Joost Dekker, ${ }^{*}$ Peter H. Mulder, ${ }^{*}$ Johannes W. J. Bijlsma, $\dagger$ and \\ Rob A. B. Oostendorp $\ddagger$ \\ * Netherlands Institute of Primary Health Care, P.O. Box 1568, 3500 BN Utrecht, The \\ Netherlands \\ $\dagger$ Department of Rheumatology, University of Utrecht, The Netherlands \\ ¥ National Institute for Research and Postgraduate Education in Physical Therapy, \\ Amersfoort, The Netherlands
}

\begin{abstract}
Exercise therapy in patients with rheumatoid arthritis (RA) or osteoarthritis (OA) is controversial, because both improvement and deterioration of the patients' condition can be expected to occur. 'The literature was searched for studies on the outcome of exercise therapy in RA- and OA-patients. Twenty-four studies were identified, comprising nine controlled studies. In the present review, these studies are critically summarized. It was found that controlled studies have only reported improvements or non-significant results; deterioration of the patients' condition has not been reported. With regard to specific modalities of exercise therapy, it was found that aerobic exercise in RA-patients has been most thoroughly studied: improvements for specific categories of outcome (e.g., walking time and other sorts of observed disability) have been repeatedly reported, while for other categories of outcome (e.g., pain) non-significant results have been consistently reported. Several methodological deficiencies (concerning randomization, blinded evaluation and power) and assets (concerning compliance) in controlled studies are noted and evaluated. It is concluded that, despite several qualifications, the available evidence is in favor of exercise therapy in RA- and OA-patients. Neglected areas of research, including comparisons between subgroups of patients, are identified and suggestions for future research are given.
\end{abstract}

\section{INTRODUCTION}

The therapeutic potential of exercise in patients with rheumatoid arthritis (RA) and osteoarthritis (OA) has been increasingly recognized in the last three decades. RA is a chronic inflammatory disease, which primarily affects the joints; inflammation of non-articular organs and generalized symptoms may also occur. OA is characterized by disintegration of articular cartilage and formation of new bone. Both RA- and OA-patients frequently have decreased physical fitness. Poor physical fitness (as manifested in relevant impairments: reduced range of motion, reduced stability of joints, muscle weakness and low aerobic fitness) is due to the underlying disease process and its consequences, to side effects of medication, and to decreased physical activity (Semble, Loeser, \& Wise, 1990). Poor physical fitness has been hypothesized to induce pain and disability. Although

Correspondence should be addressed to Dr J. Dekker. 
a causal relationship remains to be demonstrated, it has indeed been found that poor physical fitness is associated with high levels of pain and disability in arthritis patients (Ekdahl and Broman, 1992; Dekker, Boot, Woude, Bijlsma, 1992; Dekker, Tola, Audemkampe, \& Winckers, 1993). Exercise therapy aims at improvement of the patient's physical fitness and is therefore expected to cause a reduction of pain and disability in arthritis patients. Additionally, ccrtain kinds of exercise (c.g., walking exercise) aim directly at a reduction of the patient's disability. This theory, which closely corresponds to the model described by Bouchard, Shephard, Stephens, Sutton, and McPherson (1990), is schematically represented in Figure 1.

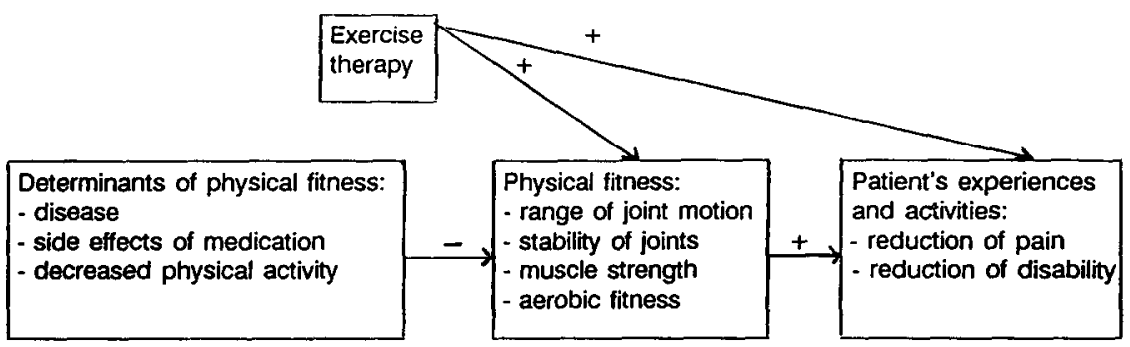

FIG. 1. Schematic representation of the rationale of exercise therapy in arthritis patients.

The expectation of beneficial effects of exercise therapy is not unquestioned, however. Exercise therapy is generally regarded as contraindicated in acute phases of RA, because it might then induce exacerbation of the inflammation (Kottke, Caspersen, \& Hill, 1984). In addition, exercise especially weightbearing exercise - might contribute to the destruction of joints, in both RA- and OA-patients. Finally, severe joint deformities, instability of joints, contractures, muscle wcakness or pain may preclude the performance of exercise (Semble et al., 1990). If patients suffering such conditions do exercise, pain and disability are expected to worsen. Thus, while exercise is expected to have therapeutic value for arthritis patients, exercise may very well have negative effects also.

This controversy has stimulated research on the outcome of exercise therapy in RA- and OA-patients. Several reviews of this research have been published (Ike et al., 1989; Semble et al., 1990; Minor, 1991). However, these reviews have some major shortcomings. Two reviews are highly selective, emphasizing the authors' own studies (Ike et al., 1989; 
Minor, 1991). The third review (Semble et al., 1990) largely covers the then available studies, but - like the other reviews - the authors failed to analyze these studies critically. (i) Former reviews failed to point out frequent methodological deficiencies. For example, former reviews have relied heavily on uncontrolled, within-group effects. (ii) Former reviews have summarized significant treatment effects, but these reviews failed to describe which effects were studied but were not found. For example, as will be demonstrated in the present review, exercise therapy has been shown to improve disability but no effect on pain has been found repeatedly. (iii) Exercise therapy comprises a range of different interventions. In former reviews no attempt has been made to determine whether these interventions have specific outcomes. Thus, a critical review concerning the question "which exercise therapy has which effects in patients with RA or OA?" seems to be indicated. Of course, one would also like to address the question "in which patients?". However, because of a lack of relevant data, this question will be dealt with in passing only.

\section{METHOD}

\section{Studies}

Computerized searches were performed in Medline (Index Medicus), Psychological Abstracts and local libraries. Manual searches were also performed. A study was included in the review if (i) it was concerned with exercise therapy in patients with RA or OA, and (ii) it described at least one within-group or between-group effect. Abstracts were excluded.

\section{Description}

The following items of information were obtained from the studies:

- Patients: number of patients; for RA-patients, the functional class according to ARA-criteria (Steinbrocker, Traeger, \& Batterman, 1949); for OA-patients, the diseased joint; duration of disease.

- Interventions: the kind of exercise therapy; and the length of the intervention. Exercise therapy was classified as follows (cf. Gerber, 1990; Hicks, 1990; Jokl, 1990): (a) mobilizing or stretching exercise, which aims at preservation or improvement of range of joint motion, (b) Muscle strengthening exercise, which can be distinguished into various types. Isometric or static exercise uses a static contraction, without a change of muscle length or movement of the joint; only muscle tension is produced. Isotonic or dynamic exercise: it uses a constant load or resistance represented by a weight; the muscle length 
changes and the joint moves. Isokinetic exercise is a dynamic exercise: the speed of joint motion is artificially fixed by means of an apparatus. (c) Aerobic or endurance exercise can occur in many different forms, e.g., jogging, swimming, cycling etc. Usually, training is geared to $60 \%$ of the maximum heart rate and higher, for 20 to $30 \mathrm{~min}$. The further distinction between weightbearing (e.g., jogging) and non-weightbearing (e.g., cycling) exercise is important in the context of arthritis patients. (d) Recreational exercise includes swimming, dancing, walking etc. This exercise does not necessarily reach the aerobic level.

- Design: the contrast of treatment groups; the way patients were assigned to treatment groups; and when measurements were performed (pre-, post- or follow up-test).

- Measures: outcome measures, grouped into categories. These categories, and the reason for distinguishing them, were as follows. Outcome measures which directly reflect the patients' experiences and activities are generally considered to be of primary importance. For arthritis patients, measures of (1) pain and (2) disability are therefore of utmost importance (Anderson, Bradley, Young, McDaniel, \& Wise, 1985; Dekker et al., 1992). A further distinction is made between (2a) disability observed by an independent person (e.g., walking time) and ( $2 b$ ) self-reported disability. Exercise therapy aims at an improvement of the patient's condition through improvement of physical fitness. Specifically, treatment aims at improvement of (3) aerobic fitness, (4) muscle strength, and (5) range of motion. Outcome measures concerning each of these categories are therefore highly relevant. A further distinction is made between (3a) oxygen uptake, ( $3 b)$ exercise time during aerobic testing, and (3c) subjective experiences during aerobic testing; (4a) muscle strength of the lower extremities, (4b) muscle strength of the upper extremities, and (4c) subjective experiences during muscle strength testing; (5a) observed range of motion of the joint and (5b) subjective flexibility of joints. A further set of measures is concerned with (6a) joint status (tenderness, swelling), (6b) morning stiffness, (7a) laboratory measures of disease activity, and $(7 \mathrm{~b})$ radiological measures of joint degeneration. These measures are highly relevant because they allow an evaluation of the effects of exercise on disease activity and joint destruction. Finally, there are measures concerning (8) general well-being, anxiety, and depression and (9) remaining variables.

- Outcome: for each (sub)category of outcome measures, it is described whether or not significant $(p<.05)$ findings were observed. Both within-group and between-group effects from pre- to post-test and from pre- to follow up-test are described. 


\section{Methodological Evaluation}

The items mentioned above allow an evaluation of four methodological core issues - whether the study was controlled, whether patients were randomly assigned to treatment groups, whether adequate statistics were reported, and the number of subjects (power). In addition, it was determined whether outcome was blindly evaluated and whether patients adhered to the exercise program (compliance).

\section{RESULTS}

\section{Rheumatoid Arthritis}

Twenty reports describing 18 studies on exercise therapy in RA-patients have been identified. These studies are described in Appendix 1. The results of these studies are summarized below. In Table 1 the betweengroup effects of the controlled studies are described.

\section{Stretching exercise}

A single study is specifically concerned with stretching exercise (Byers, 1985). In a well-controlled within-subjects design, stretching exercise was shown to improve both observed range of motion and subjective flexibility of joints (see Table 1). As will be described below, aerobic exercise has been repeatedly found not to improve range of motion. Thus, a specific effect of stretching exercise on range of motion seems to exist.

\section{Muscle strengthening exercise}

Isometric strengthening exercise has been studied in a single study (Machover \& Sapecky, 1966). Within groups, a significant improvement of muscle strength was observed in the experimental group, but the control group showed a similar trend $(p<.10)$. Unfortunately, between-group statistics were not reported. Effectively, the study is poorly controlled due to this omission.

\section{Aerobic exercise}

Aerobic exercise has been studied as part of a treatment package also comprising stretching, muscle strengthening, and/or recreational exercise. Within-group effects of such packages have been described in ten studies, both controlled and uncontrolled ones (Ekblom, Lövgren, Alderin, Fridström \& Sätterström, 1975a,b; Nordemar, Edström, \& Ekblom, 


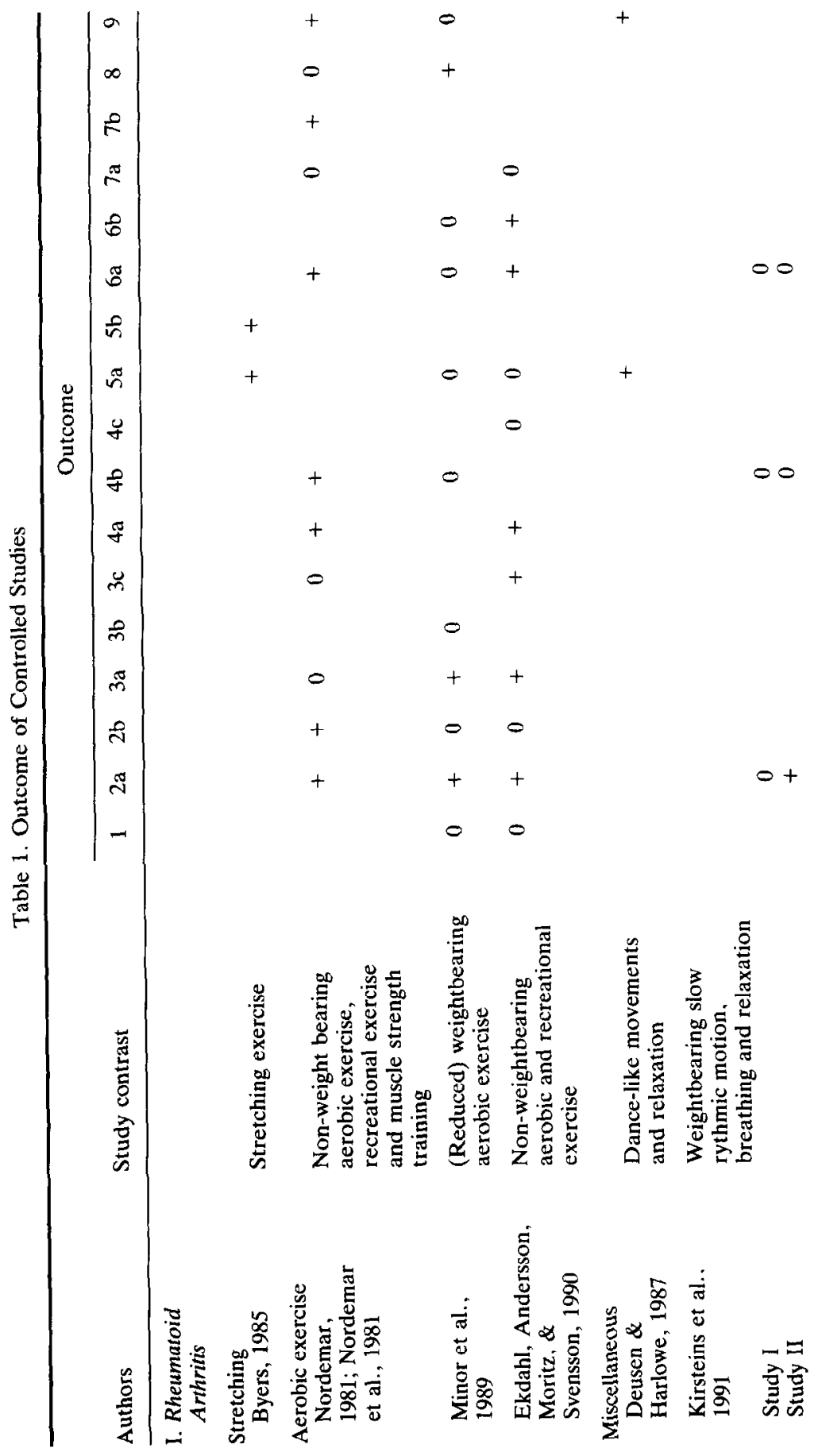




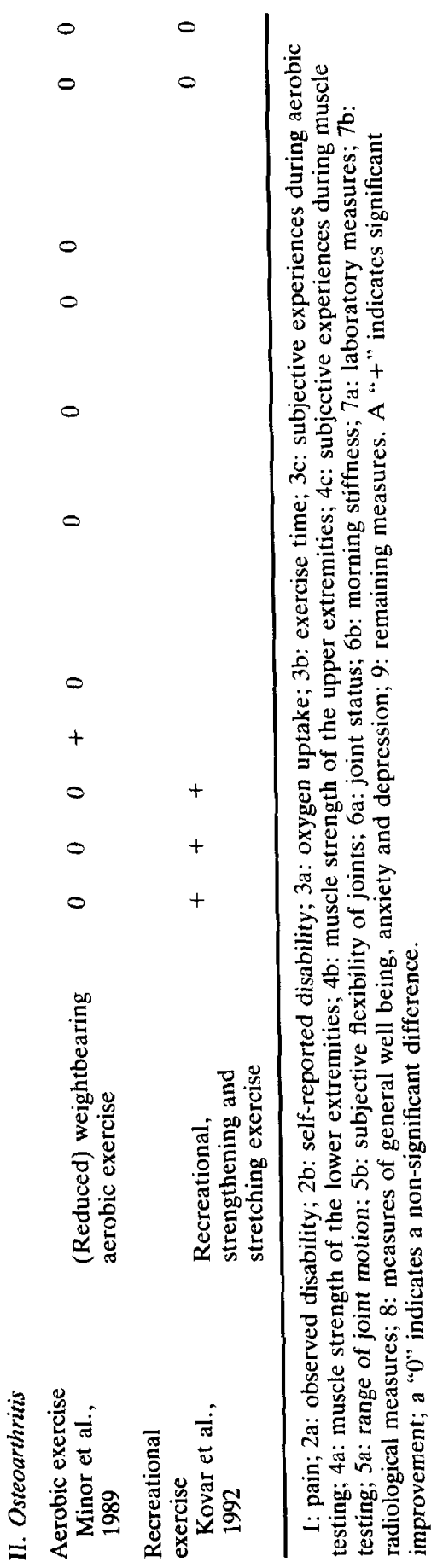


1976; Nordemar, Berg, Ekblom, \& Edström, 1976; Nordemar, Ekblom, Zachrisson, \& Lundquist, 1981; Harckom, Lampman, Banwell, \& Castor, 1985; Karper \& Evans, 1986; Lyngberg, Danneskiold-Samsoe, \& Halskov, 1988; Minor, Hewett, Webel, Anderson, \& Kay, 1989; Ekdahl, Ekman, Andersson, Melander, \& Svensson, 1990; Ekdahl, Andersson, Ekman, \& Svensson, 1992; Perlman et al., 1990). Within-groups, a significant improvement from pre- to post-test has been reported for all sub-categories of outcome measures in at least one study. The only exceptions are radiological measures (no significant change), self-reported muscle strength and subjective flexibility joints (not (statistically) evaluated). These within-group effects suggest quite an array of positive effects of the combination of these exercises.

There are six controlled studies concerning aerobic exercise. Three studies did report between-group effects, three other studies failed to do so. The between-group effects from pre- to post-test concerning the first three studies are summarized in Table 1. In the study of Nordemar (1981; Nordemar et al., 1981), the contrast between treatment groups consisted of non-weightbearing aerobic exercise in combination with recreational exercise and strengthening exercise. This combination caused a more favorable outcome for disability (observed and selfreported), muscle strength of the upper and lower extremities, joint status, radiological measures and remaining measures (training attitudes); no significant differences were observed for aerobic fitness, laboratory measures, and general well-being. In the study of Minor et al. (1989) the contrast between treatment groups consisted of (reduced) weightbearing aerobic exercise. Between groups, this exercise caused a more favorable outcome for observed disability, aerobic fitness (oxygen uptake) and general well-being; no significant differences were observed for pain, self-reported disability, exercise time, grip strength, trunk flexibility, joint status, and morning stiffness. In the study of Ekdahl, Andersson, Moritz, and Svensson (1990) the contrast between treatment groups consisted of non-weightbearing aerobic exercise and recreational exercise (in addition, the nature of strength training differed: dynamic vs static training). A more favorablc outcome was reported for observed disability, aerobic fitness (oxygen uptake and perceived exertion), muscle strength of the lower extremities, joint status, and morning stiffness. No significant differences were found for pain, self-reported disability, range of joint motion, and laboratory tests. In a 3-month follow-up test an improvement in laboratory tests $(\mathrm{Hb})$ was found; the other between-group effects appeared to be very stable.

These three controlled studies concern aerobic exercise which was or was not combined with recreational exercise and strengthening exercise. These studies can be summarized as follows. A favorable outcome 
replicated at least once (i.e., reported in at least two studies) has been found for observed disability, oxygen uptake, muscle strength of the lower extremities, and joint status. No significant differences, reported consistently in at least two studies, have been found for pain, range of joint motion, and laboratory measures. Other significant improvements and non-significant differences have been reported, but these have not yet been replicated. Significant negative outcomes have not been reported.

Three other controlled studies failed to report between group statistics (Ekblom et al., 1975a,b; Harckom et al., 1985; Lyngberg et al., 1988). One of these studies reported significant improvements in the experimental group and no significant changes in the control group; one study reported significant improvements in both the experimental and control group; and one study reported significant improvement in the experimental group, but failed to statistically evaluate the control group.

\section{Miscellaneous exercise}

Two studies are concerned with water exercise programs, which consist of stretching, muscle strengthening, and possibly some aerobic exercise (Dial \& Windsor, 1985; Danneskiold-Samsoe, Lyngberg, Risum, \& Telling, 1987). Both studies are uncontrolled, reporting improvement from pre- to post-test for observed disability, oxygen uptake, muscle strength of the lower extremities, and range of motion. "Dance-like movements" and "slow rythmic motion", in combination with breathing and relaxation techniques, have been studied in three other studies (Deusen and Harlowe, 1987; Kirsteins, Dietz, \& Hwang, 1991, study I and II). Weightbearing muscle strengthening and stretching exercises are the focus of these interventions. Within-group effects have not been reported. The between-group effects indicated favorable outcomes for observed disability, range of joint motion, and remaining measures (evaluation of exercise and rest) (see Table 1). These findings have not yet been replicated.

\section{Osteoarthritis}

Six studies concerning exercise in OA-patients have been identified. These studies are described in Appendix 2. The results of these studies are summarized below.

\section{Stretching exercise}

Stretching of hip muscles has been shown to improve range of hip motion (Leivseth, Torstensson, \& Reikeras, 1989). However, this is an uncontrolled study. 
Muscle strengthening exercise

Two studies are concerned with muscle strengthening exercise (Kreindler, Lewis, Rush, \& Schaefer, 1989; Fisher, Pendergast, Gresham, \& Calkins, $1991)$ and one study concerns diathermy and muscle strengthening exercise (Chamberlain, Care, \& Harfield, 1982). The within-group effects showed improvement for pain, disability (both observed and self-reported), and muscle strength. The study of Fisher et al. (1991) is uncontrolled and the study contrast in Chamberlain et al. (1982) concerns diathermy, not exercise. The study of Kreindler et al. (1989) comprised a control group; in the control group no significant change was observed, but the authors failed to statistically evaluate the between-group effects.

\section{Aerobic exercise}

Minor et al. (1989) studied aerobic exercise in combination with stretching and strengthening exercise. Within-groups, patients treated with this combination improved on pain, disability (observed and self-reported), aerobic fitness, grip strength, trunk flexibility, joint status, morning stiffness, anxiety, and depression. The study contrast concerned aerobic exercise. Between groups, aerobic exercise caused a more favorable outcome for aerobic fitness only (see Table 1).

\section{Recreational exercise}

The contrast in the controlled study of Kovar et al. (1992) concerns recreational exercise (fitness walking) in combination with strengthening and stretching exercise. Between groups, this treatment package caused a more favorable outcome for pain and disability (observed and selfreported); there were similar trends for general well-being and medication use.

\section{Methodological Issues}

Several methodological issues have to be raised. (i) Among the 24 studies on exercise therapy for RA- and OA-patients, there were nine controlled studies; ten studies were uncontrolled and five studies were controlled, but failed to statistically evaluate the between-group effects. (ii) In three of the controlled studies there exist difficulties with regard to the randomization of patients: some patients were allowed to change groups (Nordemar et al., 1981) or the assignment procedure has not been specified (Kirsteins et al., 1991, study I and II). However, it is not very likely that this has selectively favored positive findings: inadequate randomization has occurred in one study reporting mainly improvements 
(Nordemar et al., 1981) and two studies reporting mainly non-significant effects (Kirsteins et al., 1991, study I and II); adequate randomization has occurred in four studies reporting mainly improvements (Byers, 1985; Ekdahl, Andersson, Moritz, \& Svensson, 1990; Deusen \& Harlow, 1987; Kovar et al., 1992) and two studies reporting mainly non-significant effects (Minor et al., 1989, RA- and OA-study). (iii) In order to evaluate the meaning of non-significant differences, information on the statistical power is highly relevant. In none of the nine controlled studies has this information been given. In these nine studies, the median number of patients equals 46 (range 28-102). This suggests adequate power with regard to large effects, but inadequate power with regard to small and medium effects. (For $n=2 * 23$ and $a=.05$, the power of a study equals .85 for large effect sizes $(d=.80)$; the power equals .51 for medium effect sizes $(d=.50)$ and .16 for small effect sizes $(d=.20)$; Cohen, 1988.) (iv) In four controlled studies, measurements were taken by a person uninformed of the treatment condition (Byers, 1985; Ekdahl, Andersson, Moritz \& Svensson, 1990; Kirsteins et al., 1991, study I and II). In five other controlled studies, blinded evaluation has either not been mentioned (Nordemar et al., 1981; Minor et al., 1989, RA- and OA-study), the blinding procedure was not successful (Deusen \& Harlowe, 1987), or there was no blinded evaluation (Kovar et al., 1992). Again, it is not very likely that this has selectively favored positive findings because inadequate blinding has occurred in three studies reporting mainly positive effects (Nordemar et al., 1981; Deusen \& Harlow, 1987; Kovar et al., 1992) and two studies reporting mainly non-significant effects (Minor et al., 1989, RA- and OA-study); blinded evaluation has occurred in two studies reporting mainly positive effects (Byers, 1985; Ekdahl, Andersson, Moritz, \& Svensson, 1990) and two studies reporting mainly non-significant effects (Kirsteins et al., 1991, study I and II). (v) Compliance of patients with exercise therapy was assessed in all nine controlled studies. Although the standardization of these assessments leaves something to be desired, this is a methodological asset of these studies. Six studies reported rather high levels of compliance, one study reported a low level of compliance (Deusen \& Harlow, 1987), and in two studies no conclusion could be drawn due to missing data (Kirsteins et al., 1991, study I and II). However, because non-significant effects have been reported in studies with high levels of compliance, it is not very likely that non-significant effects can be attributed to a low level of compliance.

\section{Patients}

One would expect exercise therapy to be primarily beneficial for certain subgroups of patients. In the controlled and uncontrolled studies reviewed 
above, RA-patients differed on disease-related characteristics such as functional class (class I, II, or III) and duration of disease (ranging from 3 months to 37 years). OA-patients differed with regard to the affected joint (hip, knee, or ankle) and duration of disease (ranging from 1 to 40 years). However, none of these studies analyzed subgroups of patients differing on these or other disease-related characteristics. Most studies (controlled and uncontrolled ones) did mention that patients were advised not to exercise during acute flare ups of RA and to (temporarily) reduce their exercise level if they noticed negative effects such as pain. Unfortunately, changes in exercise level were reported only in an anecdotal way. Minor et al. (1989, RA- and OA-study) reported that seven patients dropped out due to arthritis-related conditions; Lyngberg et al. (1988) reported that two patients reduced their exercise level; Perlman et al. (1990), Kirsteins et al. (1991, study I and II), and Kovar et al. (1992) all reported one withdrawal due to arthritisrelated conditions. The other studies either stated that there were no exercise-related problems in individual patients or did not clearly address this issue.

\section{DISCUSSION}

The conclusions of this review on exercise therapy in patients with RA or OA can be summarized as follows: (i) In nine controlled studics only improvements or non-significant results have been reported; deterioration of the patients' condition has not been reported. Several qualifications of this conclusion should be mentioned. First, the controlled studies do not cover the entire range of modalities of exercise therapy for RA- and OApatients, leaving the possibility of deterioration in areas not yet studied. Second, instead of non-significant results, small or medium effects may be observed in studies on larger patient samples, with more statistical power. These effects may concern either deterioration or improvement. Third, the possibility remains that subgroups of patients are adversely affected by exercise therapy. From a practical point of view, this is an important consideration: exercise therapy might be contraindicated in patients with severe contractures or pain, for example. Anecdotal evidence does suggest that exercise therapy is contraindicated in some patients. Fourth, the randomization of patients and the blinding of evaluators were deficient in some studies. Although the distribution of these deficiencies over the studies makes it unlikely that positive outcomes have been selectively favored, these deficiencies limit the validity of those studies. Fifth, (parts of) studies describing deterioration may not have been published. These qualifications limit the possibility of drawing conclusions from the present body of research. Nevertheless, despite these qualifications, it can be 
concluded that the available evidence is in favor of exercise therapy for RA- and OA-patients. (ii) In RA-patients stretching exercise has been shown to improve range of joint motion. Aerobic exercise has repeatedly been found to improve observed disability, oxygen uptake, muscle strength of the lower extremities, and joint status. Dance-like and rythmic motion appears to improve observed disability, range of joint motion, and remaining measures (evaluation of exercise and rest), but these effects have not been replicated yet. (iii) In OA-patients a single controlled study on aerobic exercise has been identified, reporting improvement in oxygen uptake. A single controlled study on recreational exercise (fitness walking) reported improvement for pain and disability (observed and self-reported). (iv) Repeatedly observed non-significant effects of aerobic exercise in RA-patients concern pain and range of joint motion. Self-reported disability takes up a middle position: one study has reported improvement and two studies non-significant effects. The statistical power of these studies makes it unlikely that large effects for these outcome measures do exist, but small or medium effects may have gone unnoticed. A low level of compliance is an unlikely explanation of the non-significant effects. Inadequate measurement techniques are an unlikely explanation also, since techniques with proven validity have been used (Arthritis Impact Measurement Scales (AIMS), Stanford Health Assessment Questionnaire (HAQ) and goniometry).

The beneficial effects of exercise in RA-patients provide some support for the theoretical model described in Figure 1. In this model, exercise therapy is hypothesized to improve physical fitness and thereby to reduce pain and disability. In addition, (recreational) exercise therapy is thought to improve disability directly. Exercise therapy has indeed been shown to improve physical fitness (range of joint motion, muscle strength, and aerobic fitness); and, as expected, exercise has been repeatedly shown to improve observed disability, either through improvement of physical fitness or as a direct effect. However, the effects of exercise therapy on pain and self-reported disability have been less reliable, with some studies reporting improvements and other studies reporting non-significant effects. Physical fitness is possibly a primary determinant of actual disability, but only a secondary determinant of pain and self-reported disability. Other factors, such as negative affect (Watson \& Pennebaker, 1989) may be important determinants of the subjective experience of pain and disability. This would explain the discrepancy between the effects for observed disability on the one hand and pain and self-reported disability on the other.

Analyses on subgroups of patients differing on disease-related characteristics have not been reported. From a theoretical point of view, this is a striking omission. Exercise therapy aims at improvement of 
pain and disability, through improvement of range of joint motion, muscle strength and aerobic fitness (see Figure 1). Thus, beneficial effects can be specifically expected in patients with reduced range of joint motion, reduced muscle strength, or reduced aerobic fitness. In other patients, there is no particular reason to expect beneficial effects. In addition, (recreational) exercise aims at a direct improvement of disability. Again, a beneficial effect is to be specifically expected in patients with a high disability level, not in other patients. But, despite these theoretical considerations, the studies reviewed above have tacitly assumed beneficial effects to occur in all patients. For theoretical reasons, this is a very unlikely assumption.

This review has revealed neglected areas of research. In RA-patients, controlled research has focused on aerobic exercise; neglected areas include stretching and muscle strengthening exercise, with only a single controlled study in these areas (Byers, 1985). In OA-patients, only two controlled studies, focusing on aerobic exercise and recreational exercise, are available (Minor et al., 1989; Kovar et al., 1992). It has been argued that exercising of activities closely resembling daily activities is most effective (Gerber, 1990). Although some studies incorporate elements of this approach, only one fully-fledged study is available (Kovar et al., 1992). Finally, as already mentioned, there is no research which compared subgroups of patients differing on disease-related characteristics. Research in all of these areas is needed in order to further the understanding of exercise therapy in RA- and OA-patients. It is strongly recommended that future studies use well-controlled designs. Uncontrolled studies are appropriate when the therapeutic value of (exercise) therapy is entirely unknown; however, later on, controlled studies are indispensable. In addition, it is recommended that future studies use a wide range of outcome measures. These measures should cover both outcome categories where improvement is to be expected (e.g., observed disability) and categories where deterioration might occur (e.g., disease activity, joint status). Outcome measures might also include stability of joints, which appears not to have been evaluated to date.

The final conclusion of this review seems to be that a careful analysis of specific interventions and categories of outcome, in combination with a theoretical notion of how exercise affects health in arthritis patients, considerably contributes to the understanding of exercise therapy in RAand OA-patients.

\section{REFERENCES}

Anderson, K. O., Bradley, L. A., Young, L. D., McDaniel, L. K., \& Wise, C. M. (1985). Rheumatoid arthritis: review of psychological factors related to etiology, effects and treatment. Psychological Bulletin, 98, 358-387. 
Bouchard, C., Shephard, R. J., Stephens, T., Sutton, J. R., \& McPherson, B. (1990). Exercise, fitness and health. Champaign: Human Kinetics Books.

Byers, P. H. (1985). Effect of exercise on morning stiffness and mobility in patients with rheumatoid arthritis. Research in Nursing and Health, 8, 275-281.

Chamberlain, M. A., Care, G., \& Harfield, B. (1982). Physiotherapy in osteoarthrosis of the knee. International Rehabilitation Medicine, 4, 101-106.

Danneskiold-Samsoe, B., Lyngberg, K., Risum, T., \& Telling, M. (1987). The effect of water exercise therapy given to patients with rheumatoid arthritis. Scandinavian Journal of Rehabilitation Medicine, 19, 31-35.

Dekker, J., Boot, B., Woude, L. H. V. van der, \& Bijlsma, J. W. J. (1992). Pain and disability in osteoarthritis: a review of biobehavioral mechanisms. Journal of Behavioral Medicine, 15, 189-214.

Dekker, J., Tola, P., Audemkampe, G., \& Winckers M. (1993). Negative affect, pain and disability in osteoarthritis patients: the mediating role of muscle weakness. Behaviour Research and Therapy, 31, 203-206.

Deuscn, J. van, \& Harlowc, D. (1987). The efficacy of the ROM dance program for adults with rheumatoid arthritis. The American Journal of Occupational Therapy, 41, $90-95$.

Dial, C., \& Windsor, R. A. (1985). A formative evaluation of a health education-water exercise program for class II and III adult rheumatoid arthritis patients. Patient Education and Counseling, 7, 33-42.

Ekblom, B.. Lövgren, O., Alderin, M., Fridström, M., \& Sätterström, G. (1975a). Effect of short-term physical training on patients with rheumatoid arthritis. I. Scandinavian Journal of Rheumatology, 4, 90-86.

Ekblom, B., Lövgren, O., Alderin, M., Fridström, M., \& Sätterström, G. (1975b). Effect of short-term physical training on patients with rheumatoid arthritis: a six month follow-up study. Scandinavian Journal of Rheumatology, 4, 87-91.

Ekdahl, C., Andersson, S. I., Ekman, R., \& Svensson, B. (1992). Dynamic training and circulating neuropeptides in rheumatoid arthritis: a two-years follow-up study. Pain, 49, 61-64.

Ekdahl, C., Andersson, S. I., Moritz, U., \& Svensson, B. (1990). Dynamic versus static training in patients with rheumatoid arthritis. Scandinavian Journal of Rheumatology, 19, 17-26.

Ekdahl, C., \& Broman, G. (1992). Muscle strength, endurance and aerobic capacity in rheumatoid arthritis: a comparative study with healthy subjects. Annals of the Rheumatic Diseases, 51, 35-40.

Ekdahl, C., Ekman, R., Andersson, S. I., Melander, A., \& Svensson, B. (1990). Dynamic training and circulating levels of corticotropin-releasing factor, beta-lipotropin and beta-endorphin in rheumatoid arthritis. Pain, 40, 35-42.

Fisher, N., Pendergast, D. R., Gresham, G. E., \& Calkins, E. (1991). Muscle rehabilitation: its effects on muscular and functional performance of patients with knee osteoarthritis. Archives of Physical Medicine and Rehabilitation, 72, 367-374.

Gerber, L. H. (1990). Exercise and arthritis. Bulletin on the Rheumatic Diseases, 39, 1-9.

Harckom, T. M., Lampman, R. M., Banwell, B. F., \& Castor, C. W. (1985). Therapeutic value of graded aerobic exercise training in rheumatoid arthritis. Arthritis and Rheumatism, 28, 32-39.

Hicks, J. E. (1990). Exercise in patients with inflammatory arthritis and connective tissue disease. Rheumatic Disease Clinics of North America, 16, 845-870.

Ike, R. W., Lampman, R. M., \& Castor, C. W. (1989). Arthritis and aerobic exercise: a review. The Physician and Sports Medicine, 17, 128-138.

Jokl, P. (1990). Prevention of disuse muscle artrophy in chronic arthritides. Rheumatic Disease Clinics of North America, 16, 837-844.

Karper, W. B., \& Evans, B. W. (1986). Cycling program effects on one rheumatoid arthritic. American Journal of Physical Medicine, 65, 167-172.

Kirsteins, A. E., Dietz, F., \& Hwang, S. M. (1991). Evaluating the safety and potential 
use of a weight-bearing exercise, Tai-Chi Chuan, for rheumatoid arthritis patients. American Journal of Physical Medicine and Rehabilitation, 70, 136-141.

Kottke, T. E., Caspersen, C. J., \& Hill, C. (1984). Exercise in the management and rehabilitation of selected chronic diseases. Preventive Medicine, 13, 47-65.

Kovar, P. A., Allegrante, J. P., Mackenzie, C. R., Petersen, M. G. E., Gutin, B., \& Charlson, M. E. (1992). Supervised fitness walking in patients with osteoarthritis of the knee. Annals of Internal Medicine, 116, 529-534.

Kreindler, H., Lewis, C. B., Rush, S., \& Schaefer, K. (1989). Effects of three exercise protocols on strength of persons with osteoarthritis of the knee. Topics in Geriatric Rehabilitation, 4, 32-39.

Leivseth, G., Torstensson, J., \& Reikeras, O. (1989). Effects of passive muscle stretching in osteoarthritis of the hip. Clinical Science, 76, 113-117.

Lyngberg, K., Danneskiold-Samsoe, B., \& Halskov, O. (1988). The effect of physical training on patients with rheumatoid arthritis: changes in disease activity, muscle strength and aerobic capacity. Clinical and Experimental Rheumatology, 6, 253-260.

Machover, S., \& Sapecky, A. J. (1966). Effect of isometric exercise on the quadriceps muscle in patients with rheumatoid arthritis. Archives of Physical Medicine and Rehabilitation, 47, 737-741.

Minor, M. A. (1991). Physical activity and management of arthritis. Annals of Behavioral Medicine, 13, 117-124.

Minor, M. A., Hewett, J. E., Webel, R. R., Anderson, S. K., \& Kay, D. R. (1989). Efficacy of physical conditioning exercise in patients with rheumatoid arthritis and osteoarthritis. Arthritis and Rheumatism, 32, 1396-1405.

Nordemar, R. (1981). Physical training in rheumatoid arthritis: a controlled long-term study I. Scandinavian Journal of Rheumatology, 10, 17-23.

Nordemar, R., Berg, U., Ekblom, B., \& Edström, L. (1976). Changes in muscle fibre size and physical performance in patients with rheumatoid arthritis after 7 months' physical training. Scandinavian Journal of Rheumatology, 5, 233-238.

Nordemar, R., Edström, L., \& Ekblom, B. (1976). Changes in muscle fibre size and physical performance in patients with rheumatoid arthritis after short-term physical training. Scandinavian Journal of Rheumatology, 5, 70-76.

Nordemar, R., Ekblom, B., Zachrisson, L., \& Lundquist, K. (1981). Physical training in rheumatoid arthritis: a controlled long-term study. I. Scandinavian Journal of Rheumatology, 10, 17-23.

Perlman, S. G., Connell, K. J., Clark, A., Robinson, M. S., Conlon, P., Gecht, M., Caldron, P., \& Sinacore, J. M. (1990). Dance-based aerobic exercise for rheumatoid arthritis. Arthritis Care and Research. 3, 29-35.

Semble, E. L., Loeser, R. F., \& Wise, C. M. (1990). Therapeutic exercise for rheumatoid arthritis and osteoarthritis. Seminars in Arthritis and Rheumatism, 20, 32-40.

Steinbrocker, D., Traeger, C. H., \& Batterman, R. C. (1949). Therapeutic criteria in rheumatoid arthritis. Journal of the American Medical Association, 140, 659-662.

Watson, D., \& Pennebaker, J. W. (1989). Health complaints, stress and distress: exploring the central role of negative affectivity. Psychological Review, 96, 234-254. 
Exercise Therapy in Patients with RA and OA
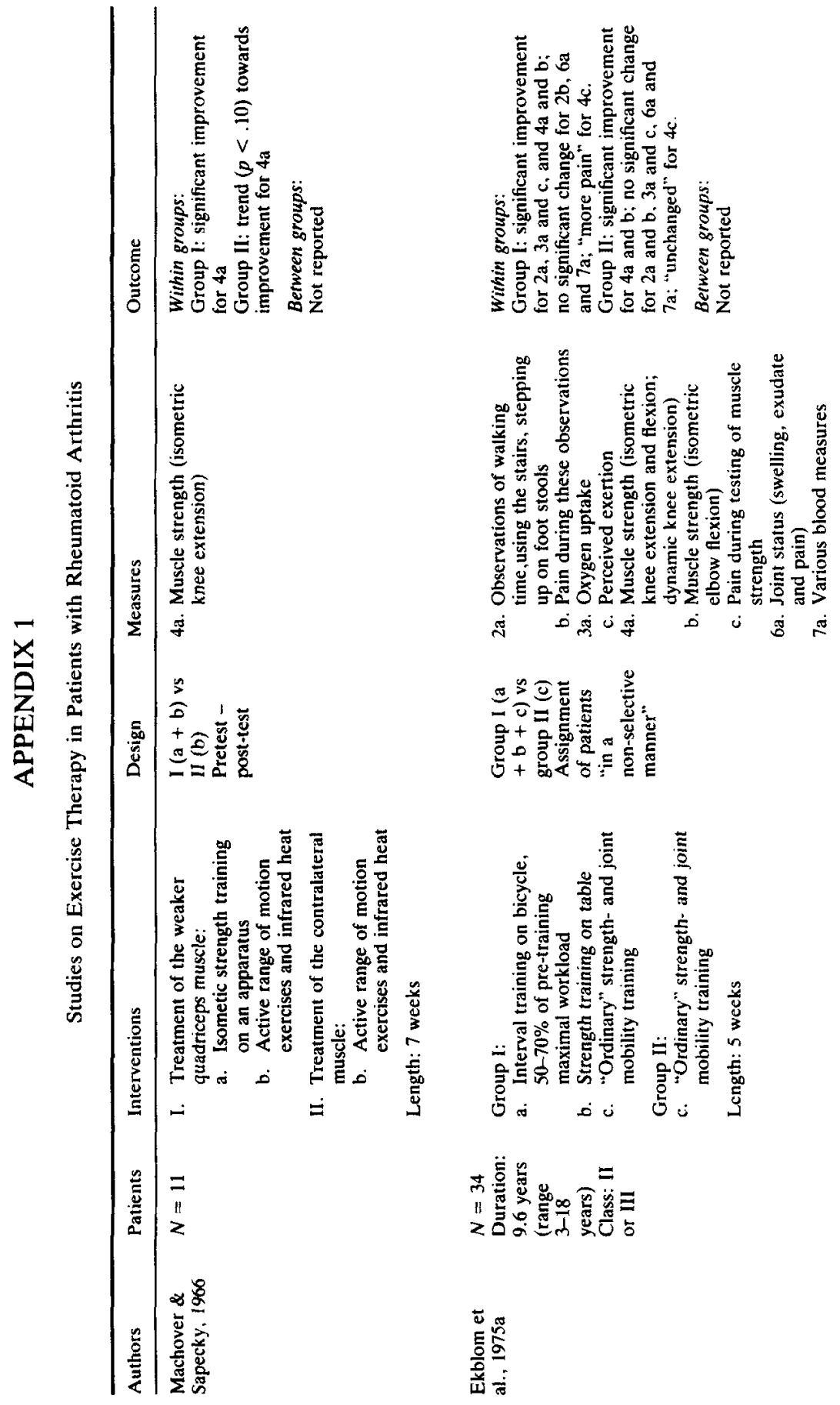

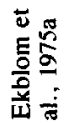




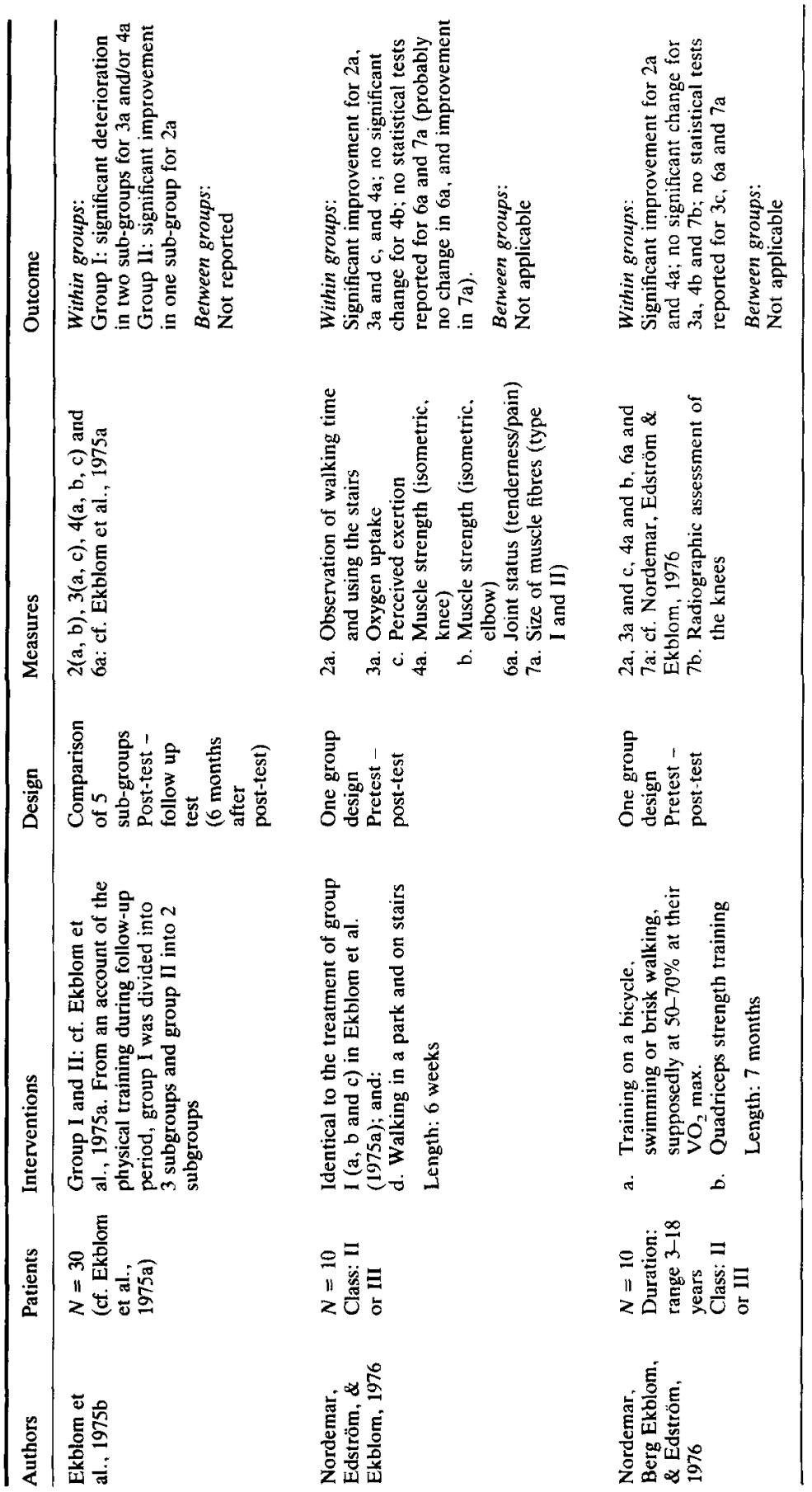




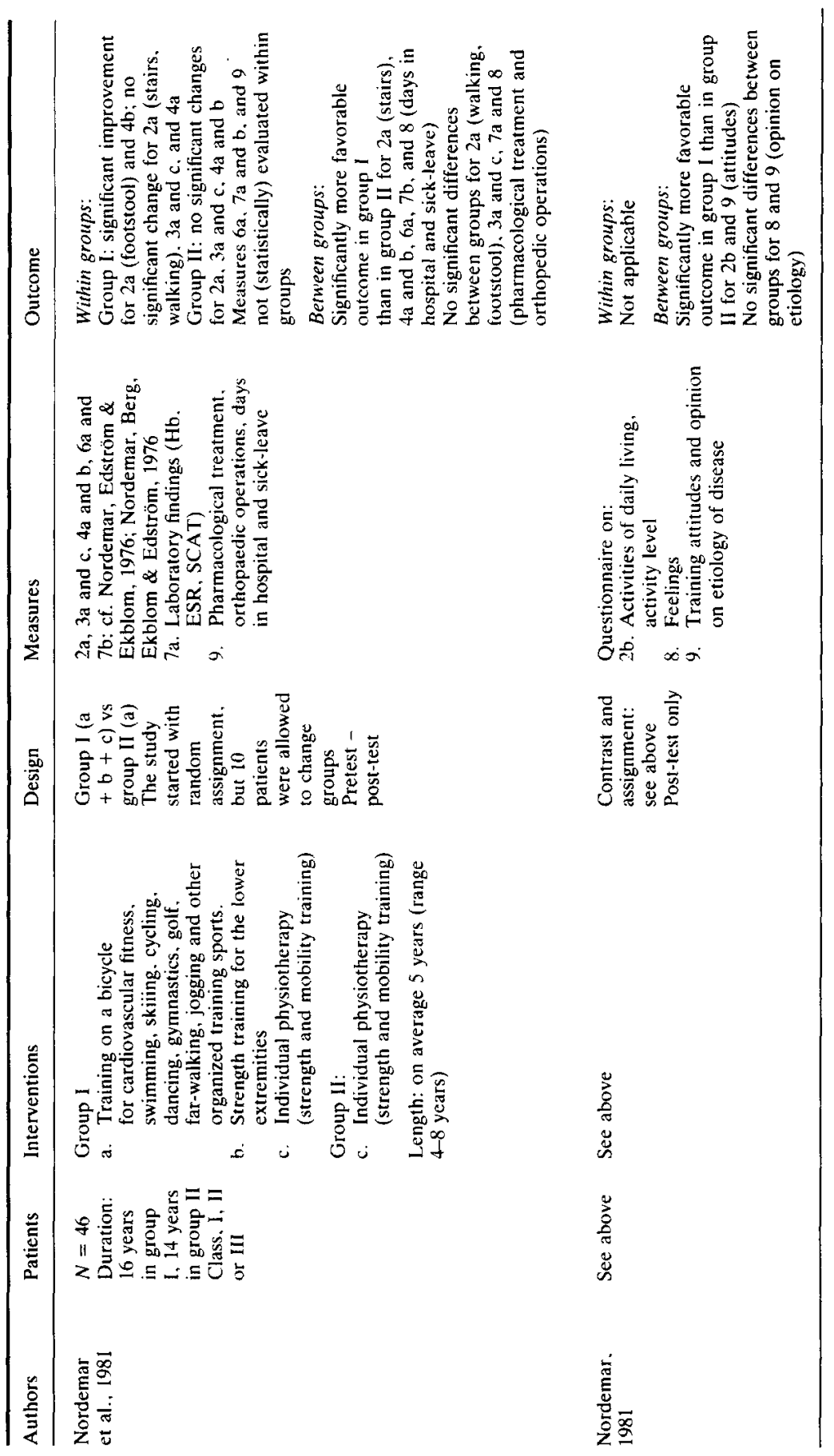


J. Dekker et al.
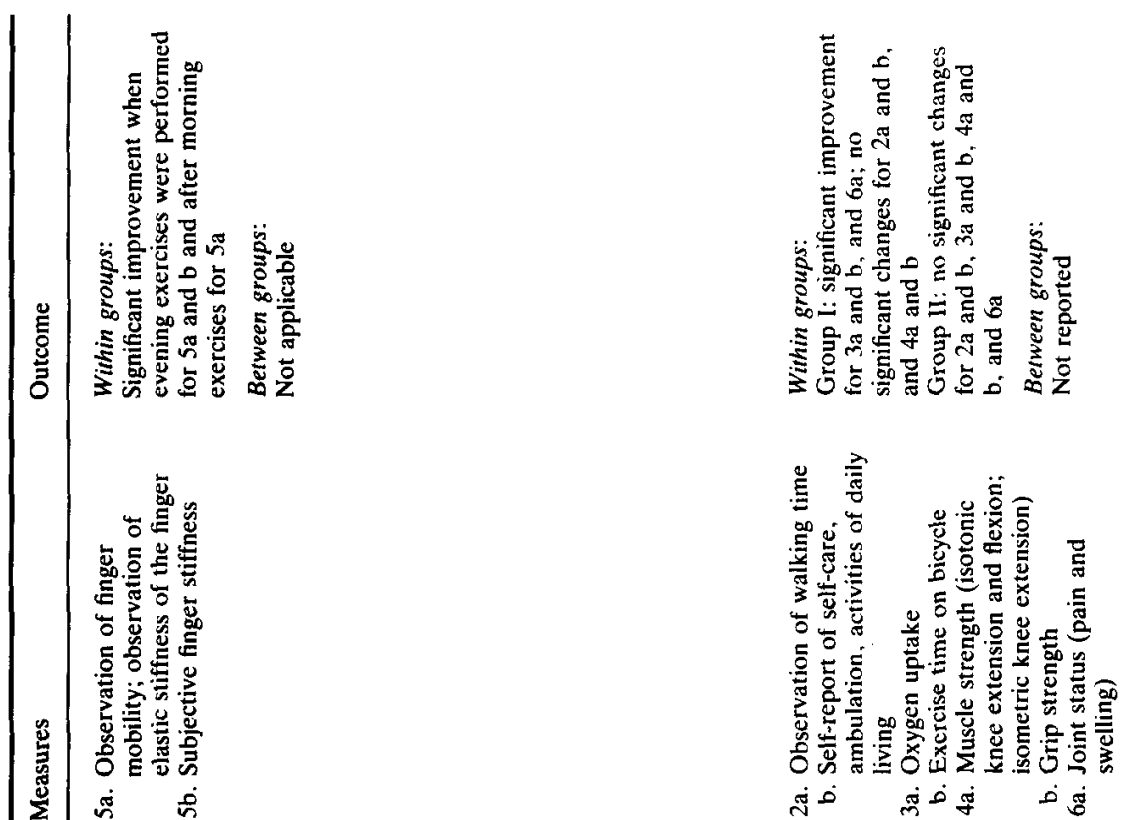

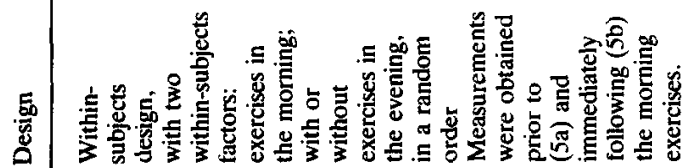
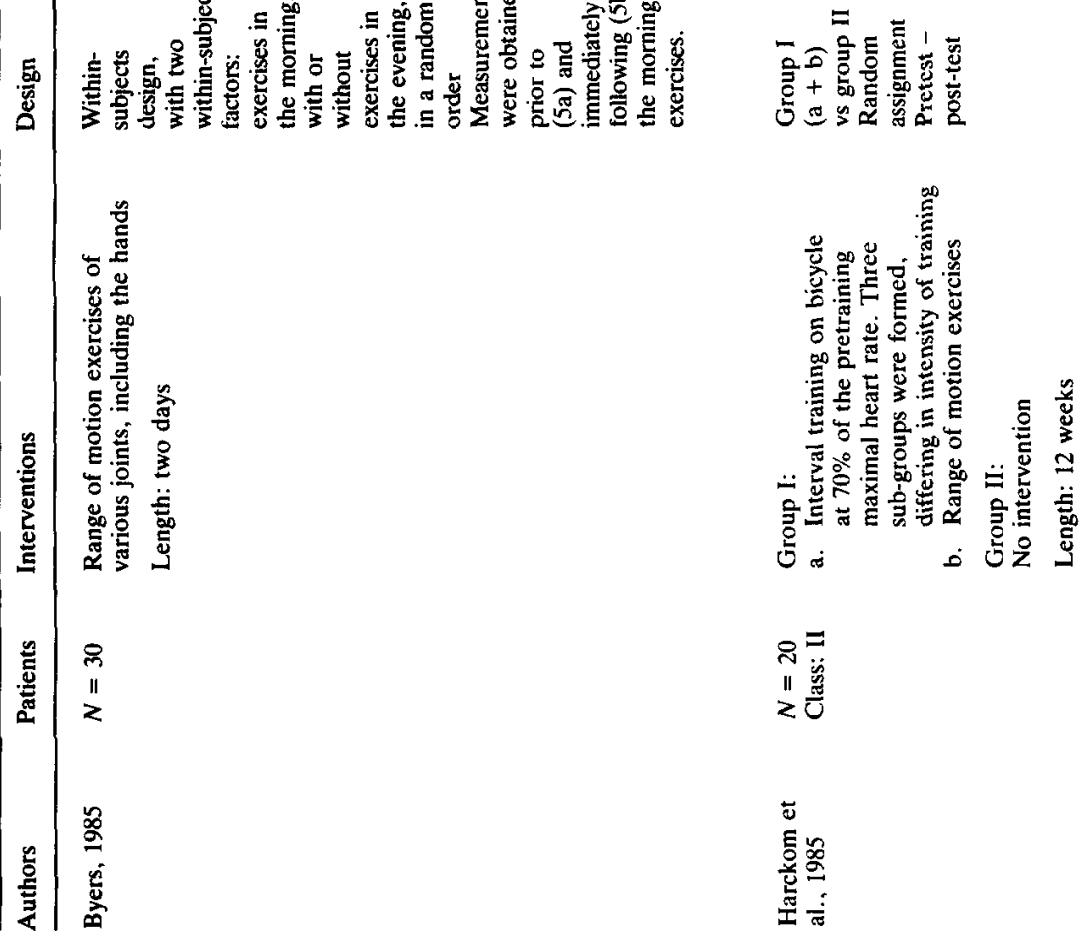

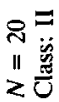

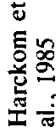




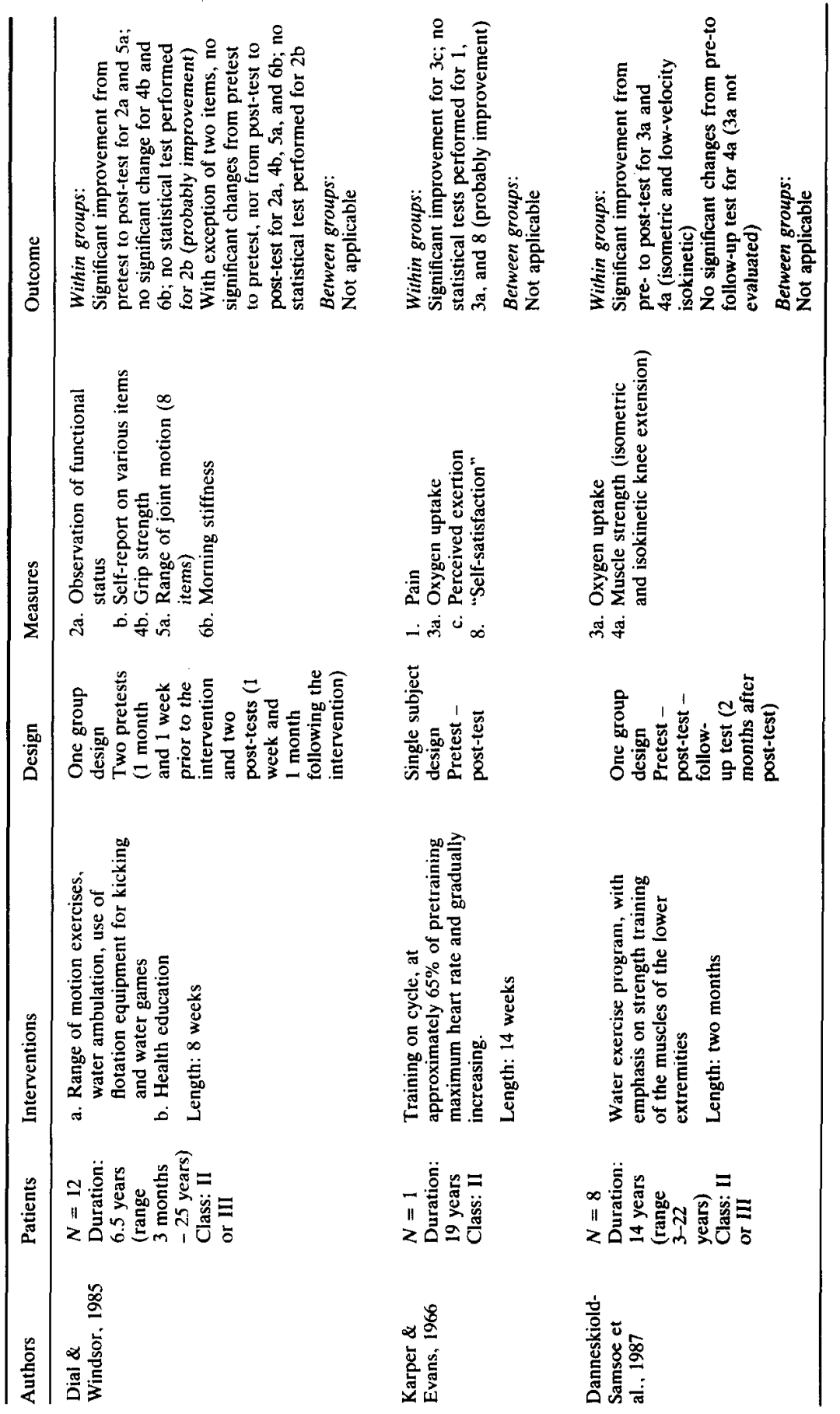


J. Dekker et al.

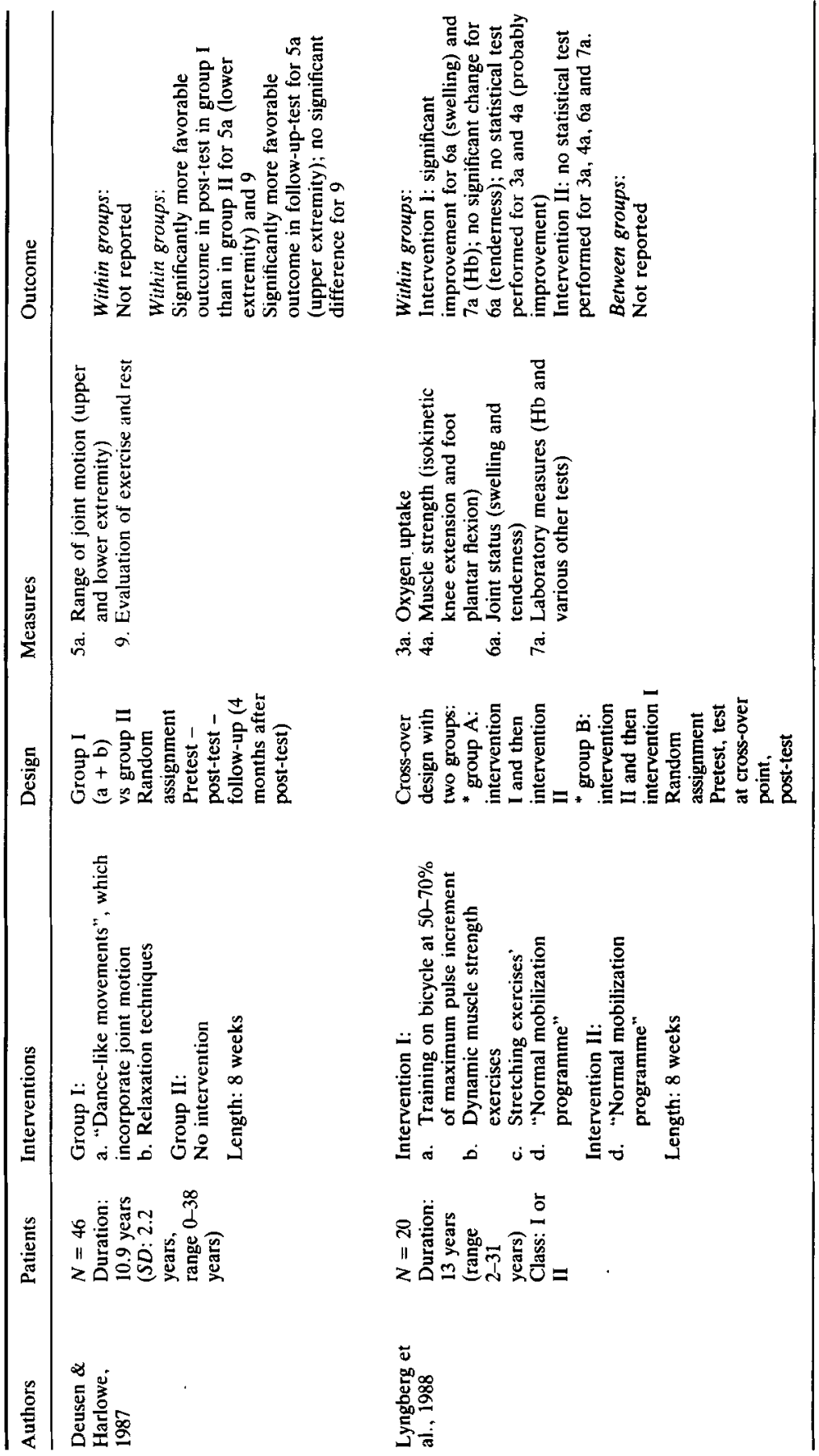




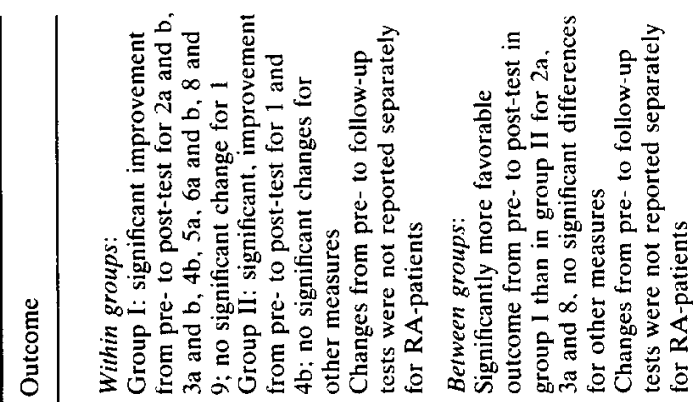

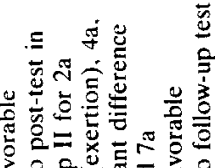

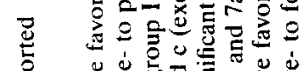

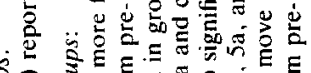

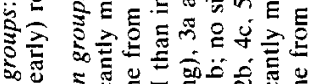

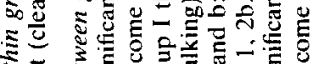

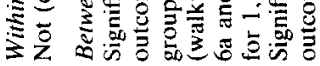

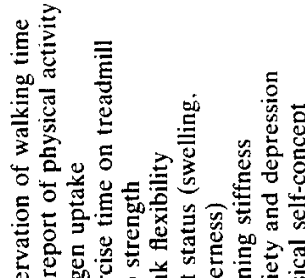

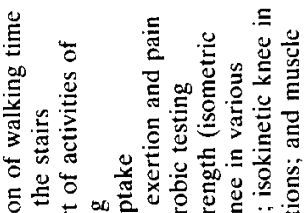

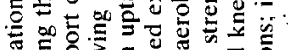

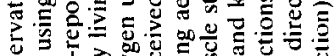

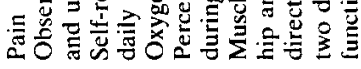

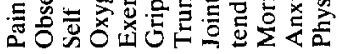

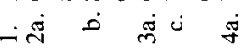

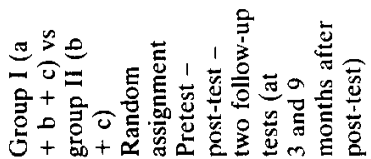

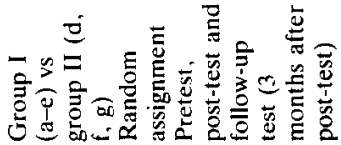
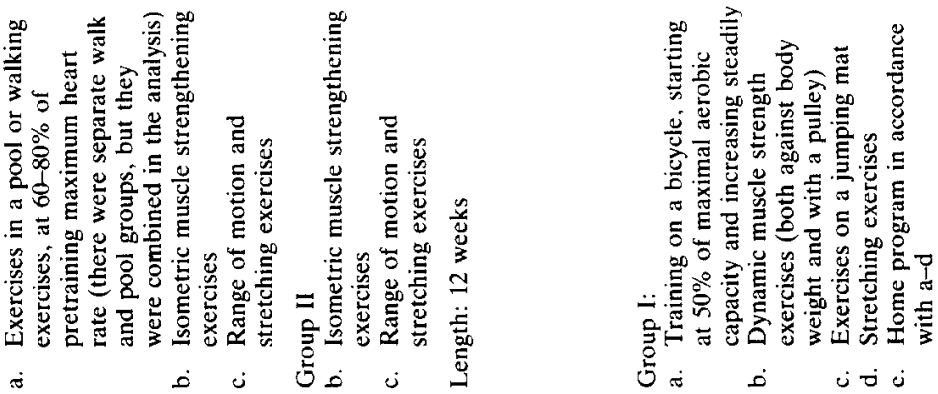

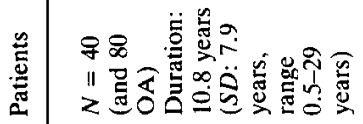

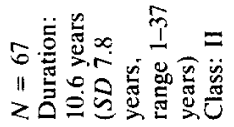

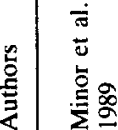

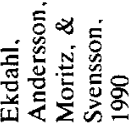


J. Dekker et al.

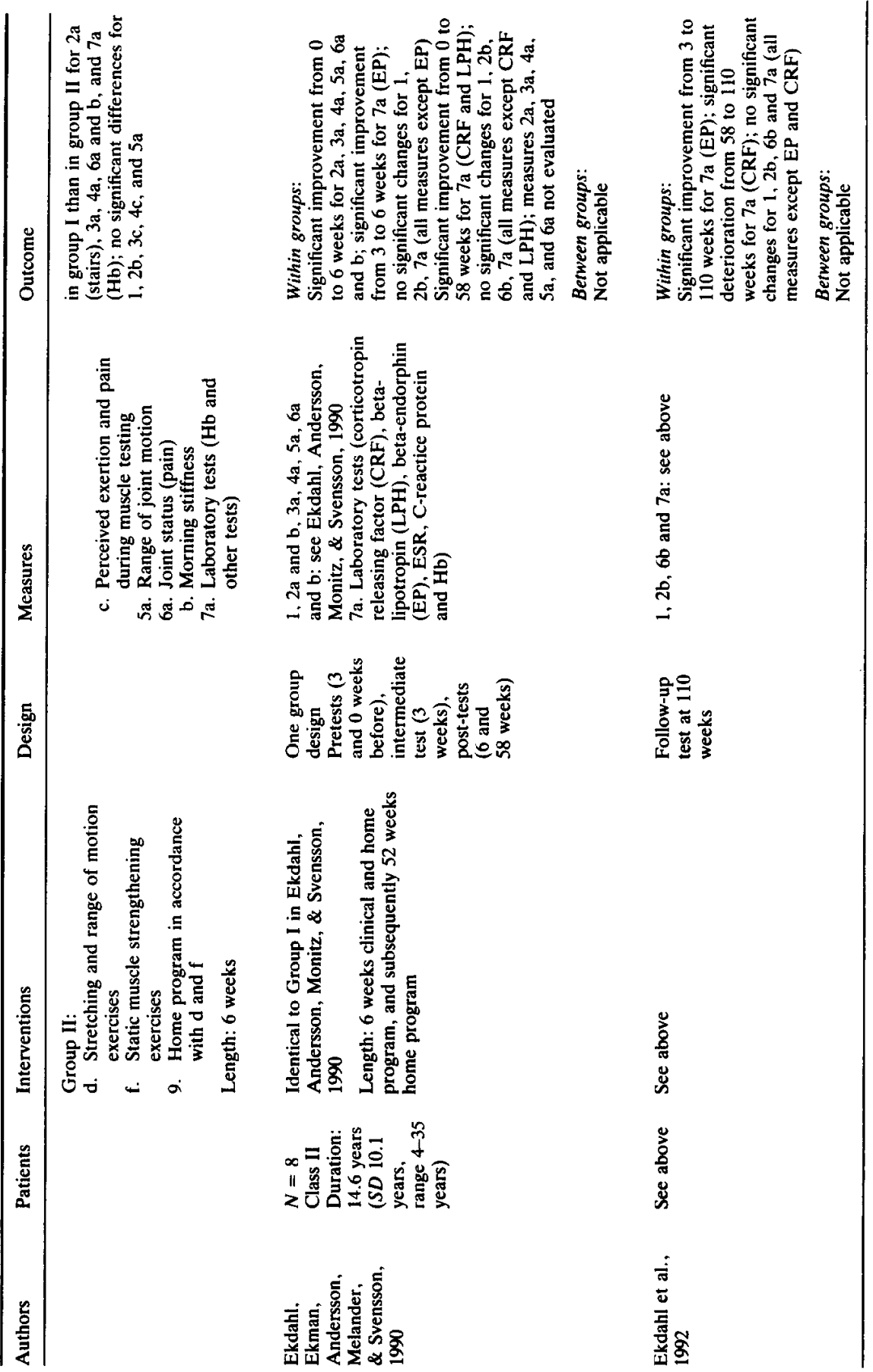


Exercise Therapy in Patients with RA and OA

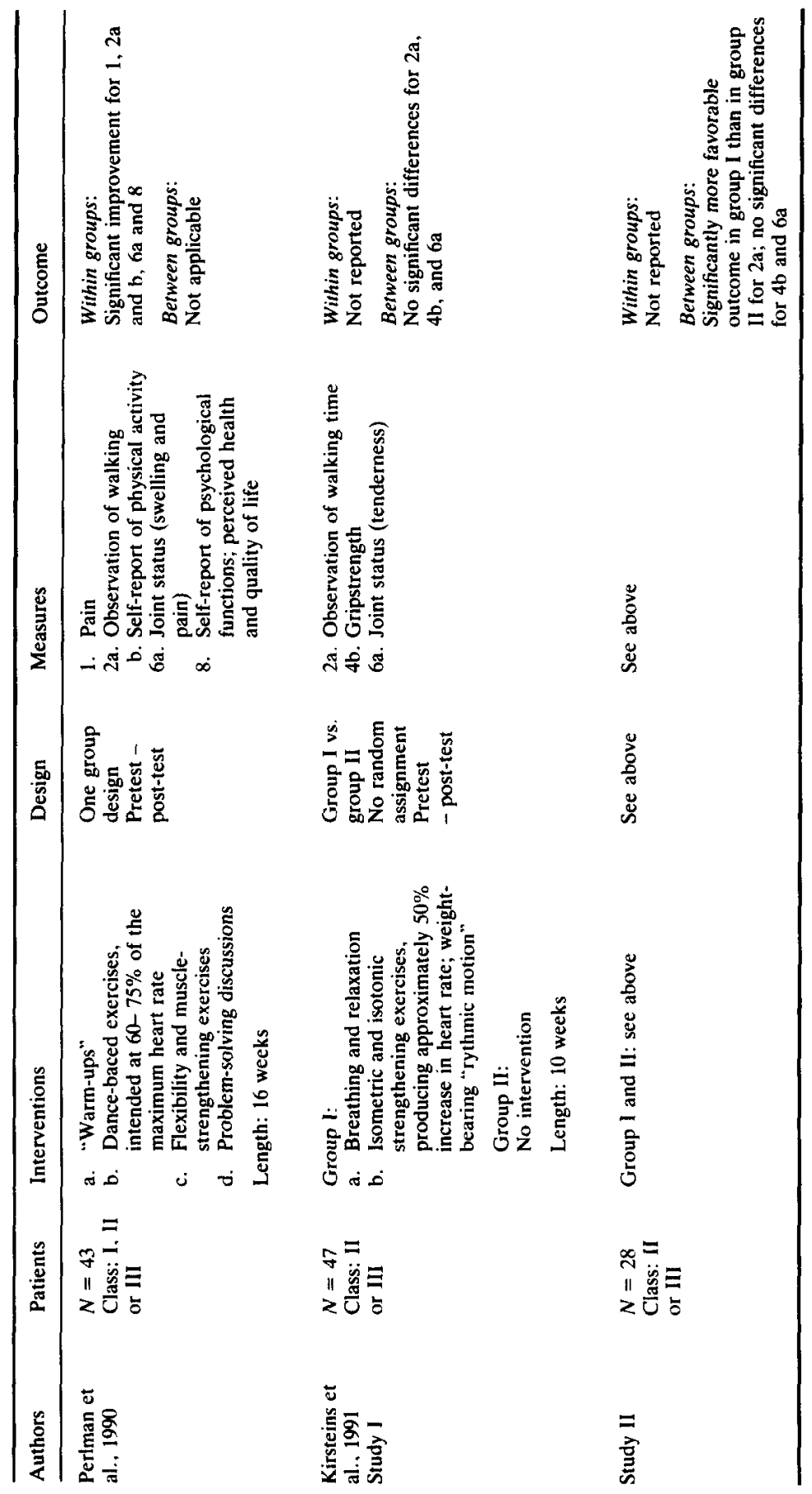




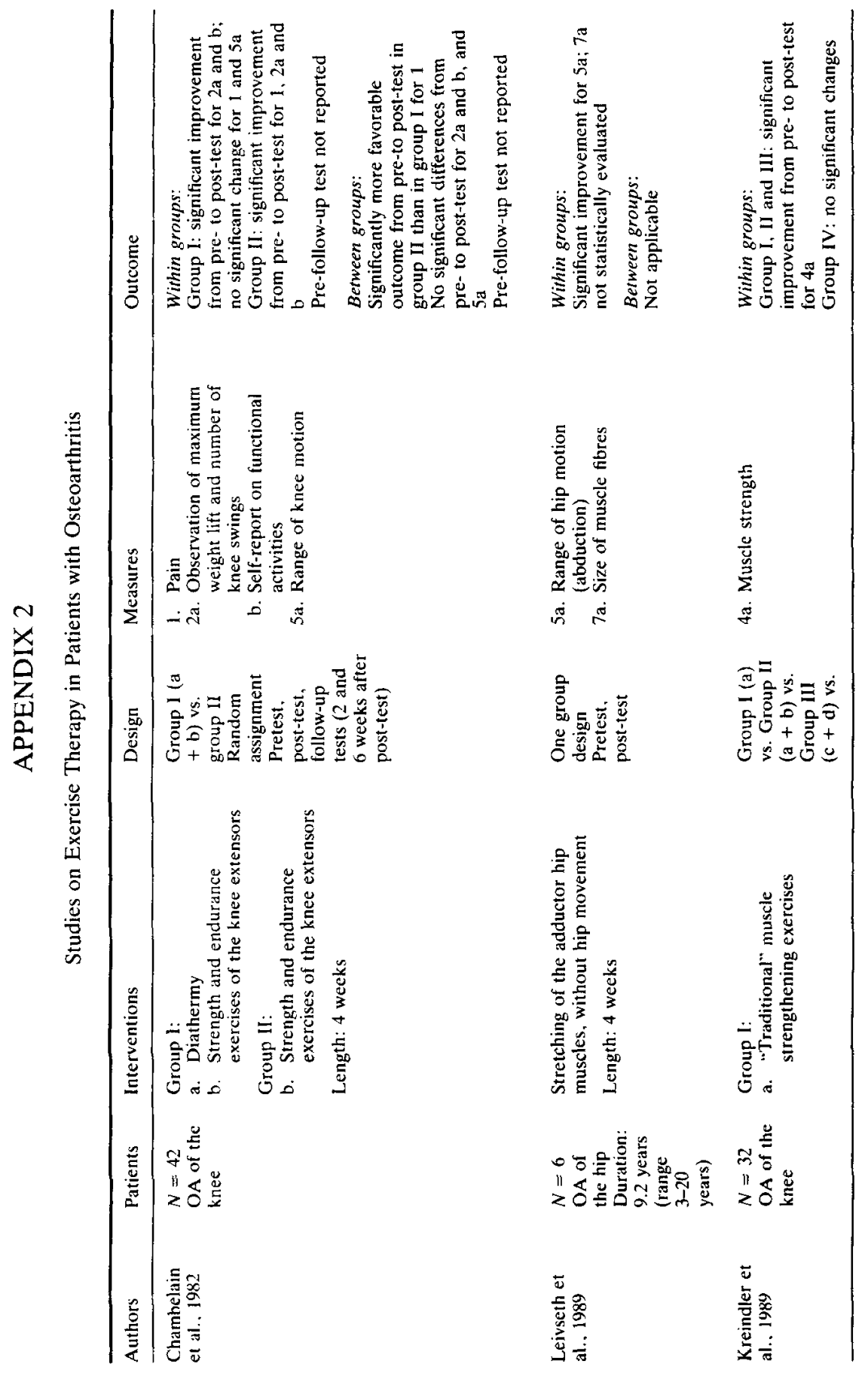


Exercise Therapy in Patients with RA and OA

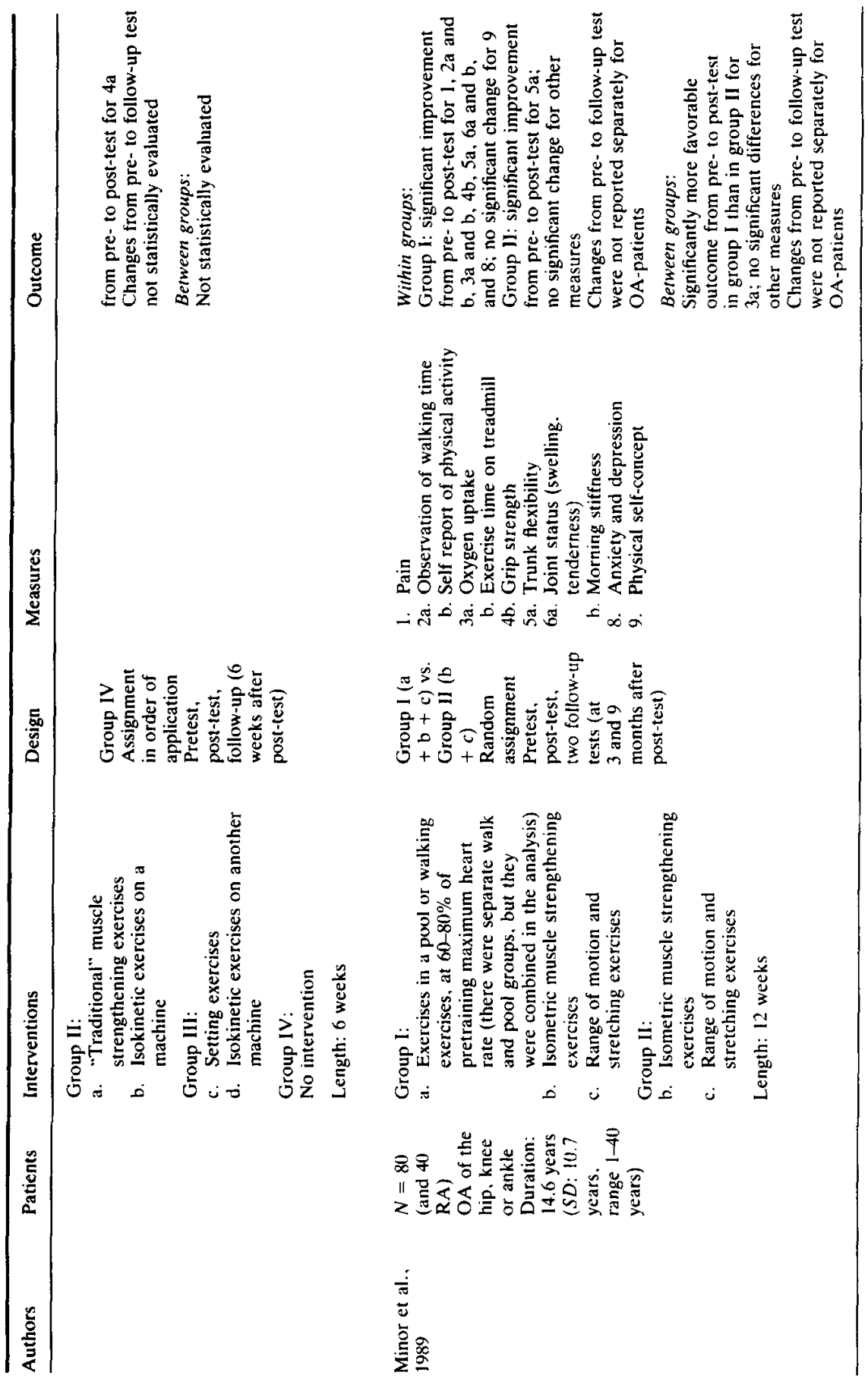


J. Dekker et al.
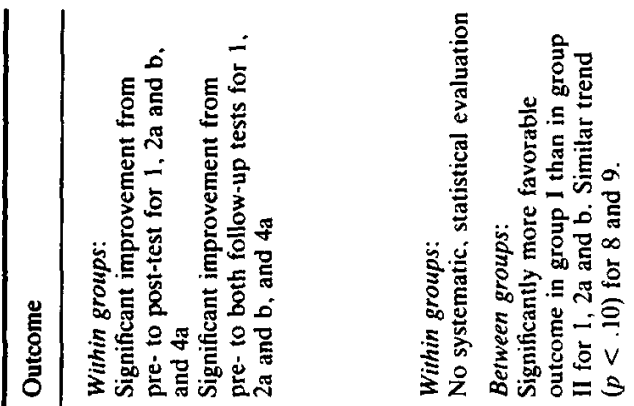

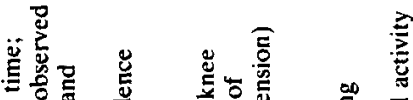

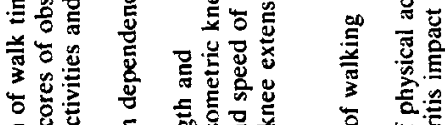

论

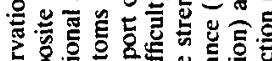

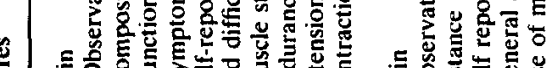

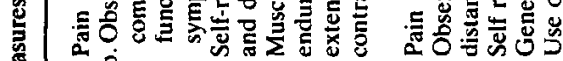

至 म

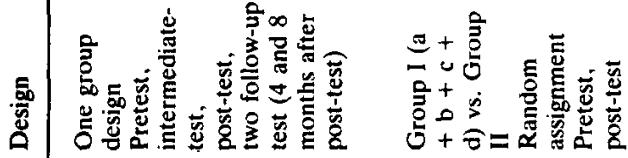
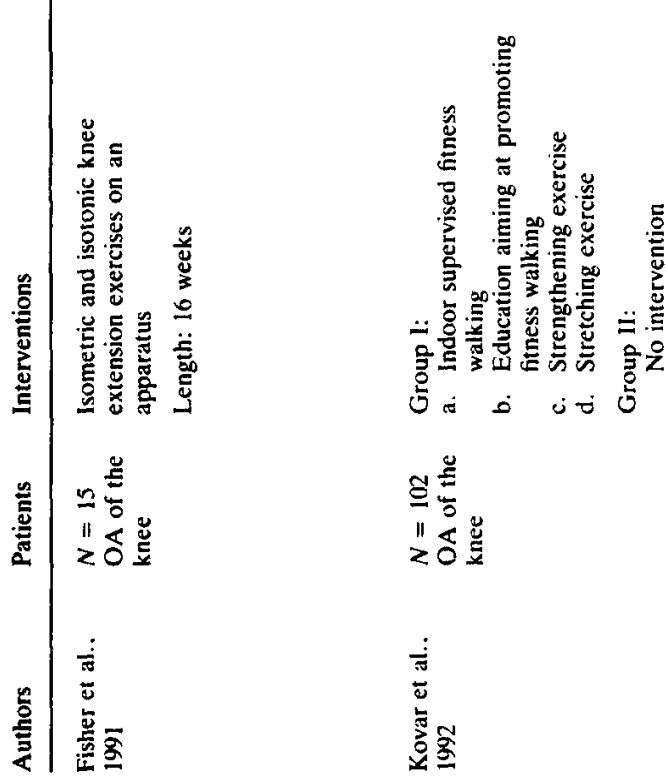

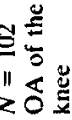

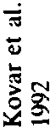

